Iranian Quarterly Journal of Breast Disease 2018; 11(2):46.

\title{
The Comparison of Sexual Satisfaction and Body Image between Women with Breast Cancer after Treatment and Healthy Middle-Aged Women: A Cross-Sectional Study
}

Fathi Aghdam Gh: Consulting Department, Faculty of Humanities, Islamic Azad University of Abhar, Abhar, Iran

Haghighat S: Quality of Life Department, Breast Cancer Research Center, Motamed Cancer Institute, ACECR, Tehran, Iran

Dorri S: Medical Informatics Department, Breast Cancer Research Center, Motamed Cancer Institute, ACECR, Tehran, Iran

Nazeri N: Medical Informatics Department, Breast Cancer Research Center, Motamed Cancer Institute, ACECR, Tehran, Iran

Ajorbandian A: Faculty of Humanities, Islamic Azad University of Abhar \& Breast Cancer Research Center, Motamed Cancer Institute, ACECR, Tehran, Iran

Corresponding Author: Amene Ajorbandian, mahtab.ajorbandian@gmail.com

\begin{abstract}
Introduction: In Iran, many of the women with breast cancer complain of communication problems with their spouses after diagnosis and treatment. One of the most important issues in this area is reducing their psychological problems and improving their quality of life. The present study was conducted to compare sexual satisfaction and body image between women with breast cancer after treatment and healthy women.
\end{abstract}

Methods: This was a cross-sectional descriptive study. A total of 146 women, aged $<50$ years, were selected by convenience sampling from healthy women $(n=73)$ and women with breast cancer after treatment $(n=73)$ who were referred to the Breast Disease Clinic of Motamed Cancer Institute, Tehran, Iran. The Sexual Satisfaction Scale for Women (SSSW) and Body Image Concern Inventory (BICI) were used for data collection.

Results: The mean sexual satisfaction score for the women was significantly higher than that for the breast cancer patients $(102.06 \pm 17.06$ vs $80.6 \pm 20.97, \mathrm{p}<0.001)$. Also, healthy women had fewer body image concerns compared with the patients $(37.85 \pm 10.85$ vs $46.11 \pm 16.99$, $\mathrm{p}<0.001)$. The difference between the groups was significant for each component of the variables $(\mathrm{p}<0.05)$.

Conclusion: Breast cancer survivors have a lower sexual satisfaction and more body image concerns compared with healthy women. These results show the importance of providing counseling for these patients to improve their quality of life.

Keywords: Breast Cancer, Sexual Satisfaction, Body Image, Cross-sectional study 


\title{
مقايسه رضايتمندى جنسى و تصوير بدنى در زنان مبتلا به سرطان پستان پس از درمان با زنان سالم ميانسال: يك مطالعه مقطعى
}

\author{
قربان فتحى اقدم: كروه مشاوره، دانشكده علوم انسانى، دانشكاه آزاد اسلامى واحد ابهر، ابهر، ايران

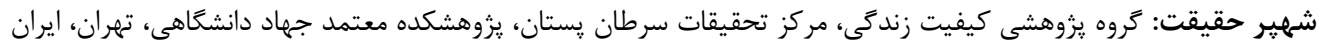

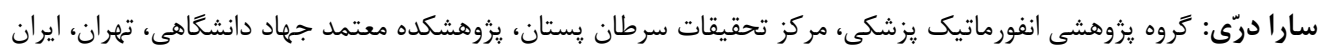

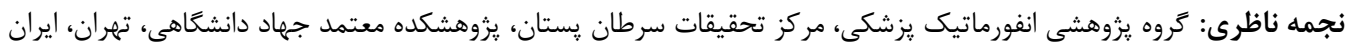

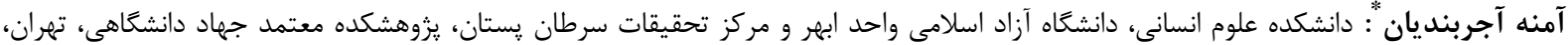

مقدمه: در ايران بسيارى از زنان مبتلا به سرطان پستان از مشكلات ارتباطى با همسر يس از تشخيص و درمان بيمارى

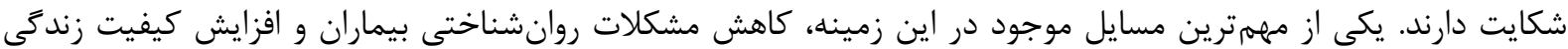

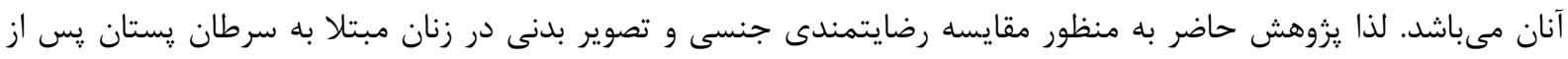
درمان با زنان سالم انجام شده است. روش بررسى: اين يزوهش از نوع مقطعى (توصيفى- تحليلى) است. جامعه آن شامل زنان سالم و زنان مبتلا به سرطان پستان يس از درمان مراجعه كننده به كلينيك بيمارىهاى يستان يزوهشكده معتمد جهاد دانشخاهى بود كه زئ زير •له سال داشتهاند.

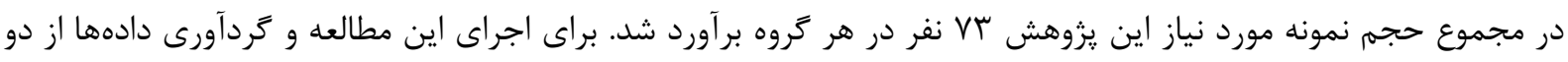

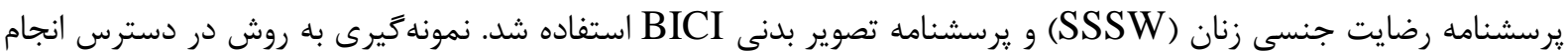

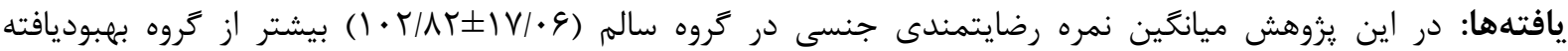

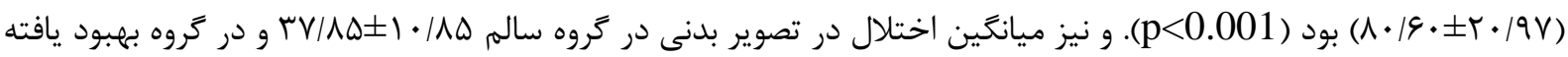

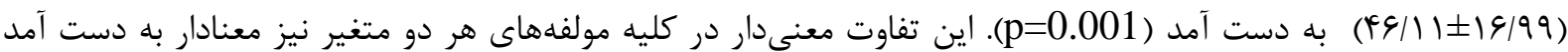

نتيجهكيرى: نتايج حاصل از اين يزوهش نشان داد رضايتمندى جنسى و تصوير بدنى در زنان بهبود يافته از سرطان رِانتان

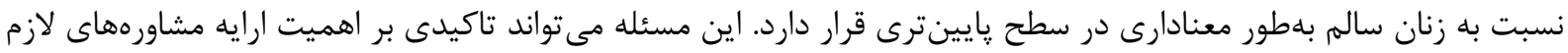

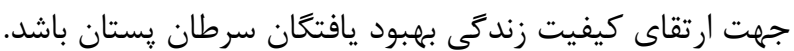
وازههاى كليدى: سرطان يستان، رضايتمندى جنسى، تصوير بدنى، مطالعه مقطعى 
در گروههايى دارد كه دجار مشكلات نارضايتى در تصوير

بدنى بودند (9).

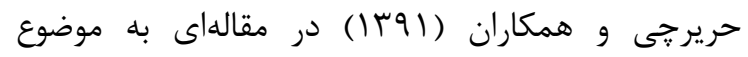

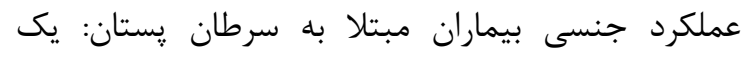

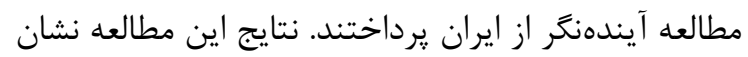

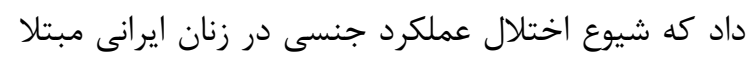

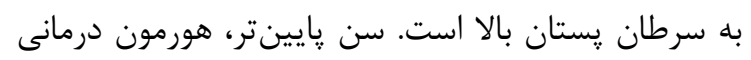

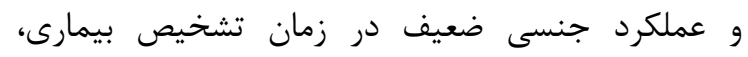
بيشترين عوامل بيشكويى كننده اختلالات متعاقب درمان

هستند (•). (1).

سرطان يستان نيز مانند هر نوع سرطان جنبههاى مختلف (ن) مانف

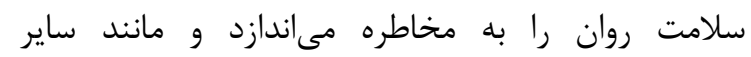

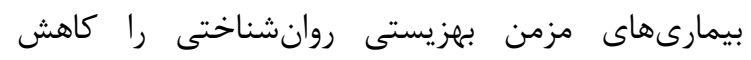

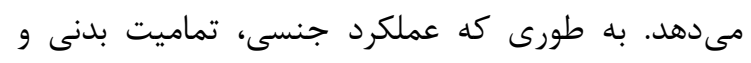

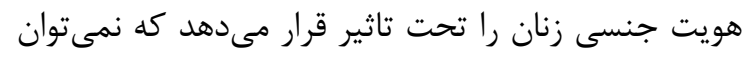

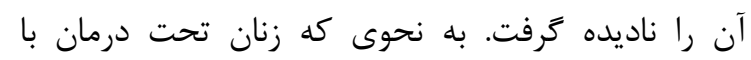

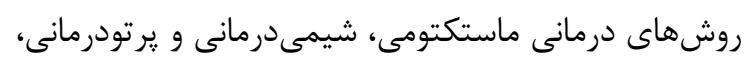

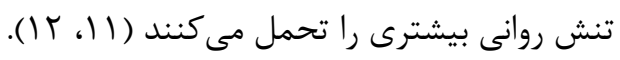

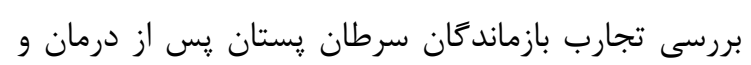

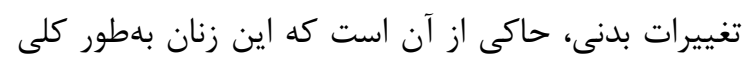

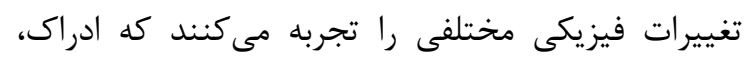

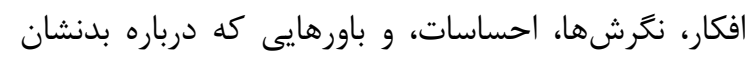

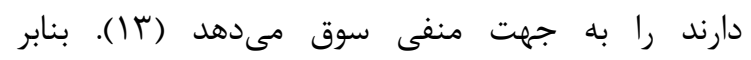

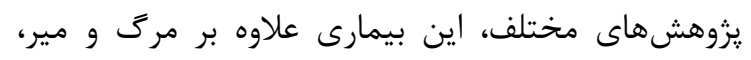

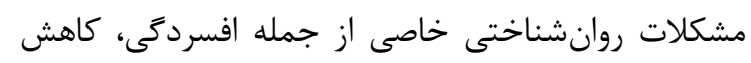

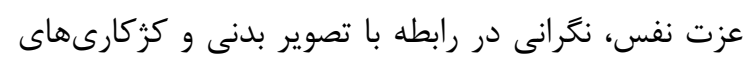

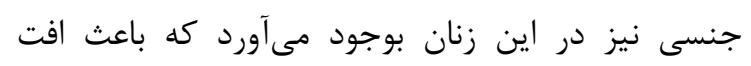

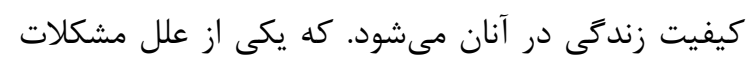

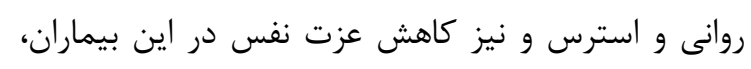

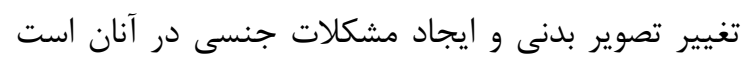

در ايران بسيارى از بانوان مبتلا به سرطان پستان در

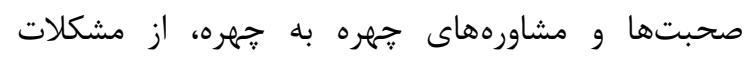
ارتباطى با همسر يس از تشخيص و درمان بيمارى شكايت

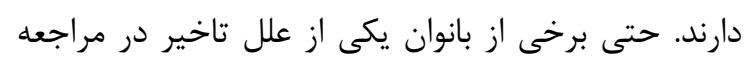

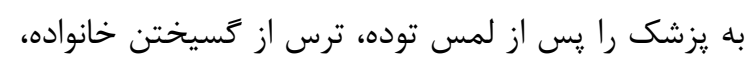

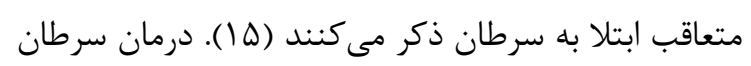

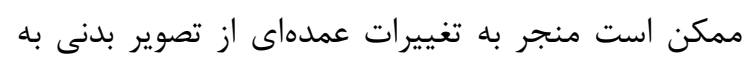

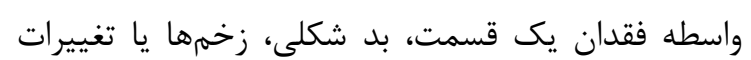

سرطان پستان سومين سرطان شايع در جهان و شايعترين

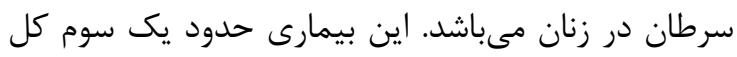

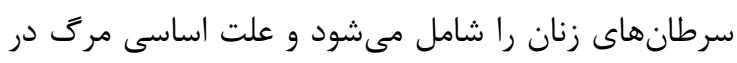

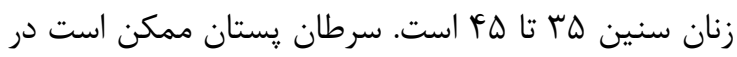

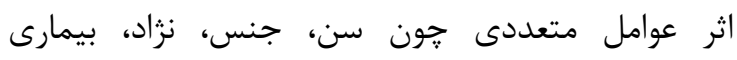

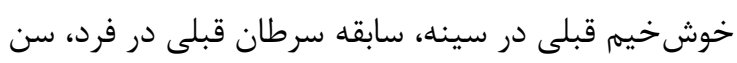

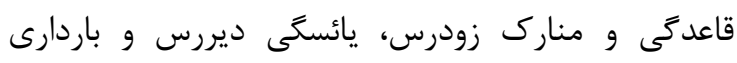

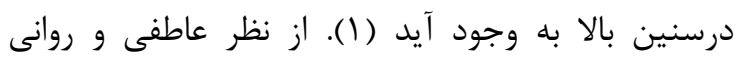

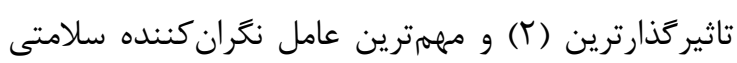

در بين زنان است (بات).

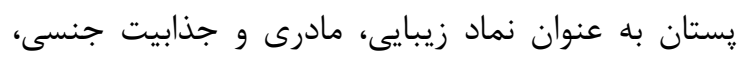

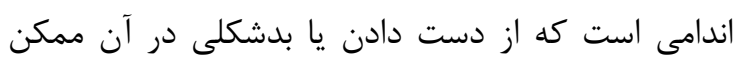

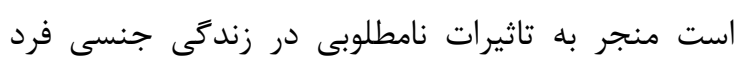

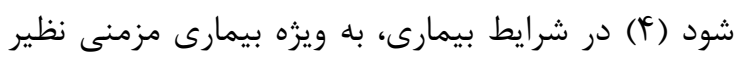

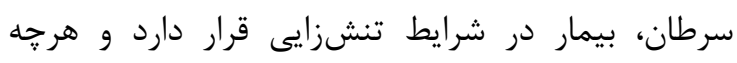

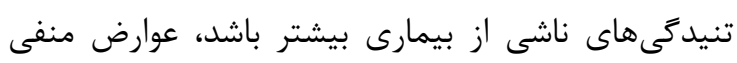

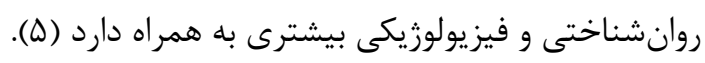

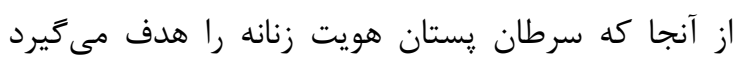

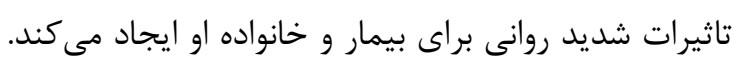

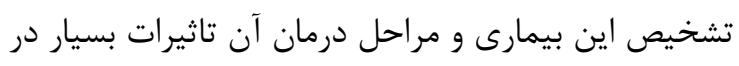

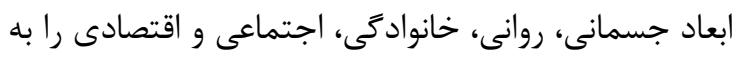

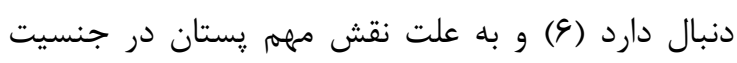
زنان، واكنش زن به بيمارى حقيقى يا مشكوى به سبه سرطان

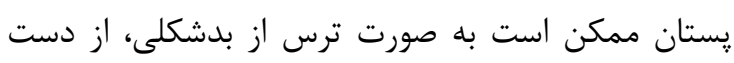

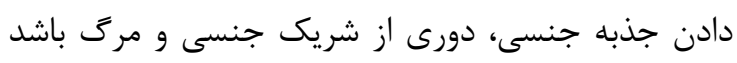

يزوهشها نشان دادهاند كه مشكلات جنسى به طور

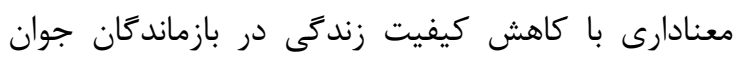

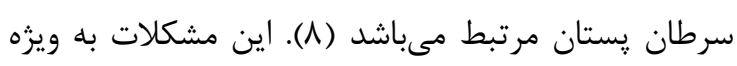

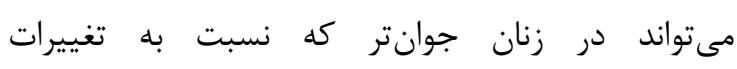

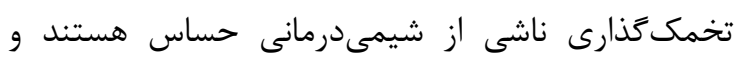

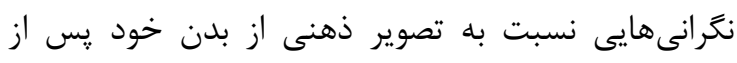

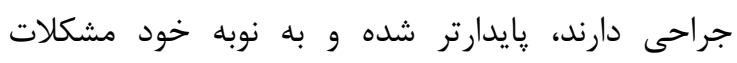

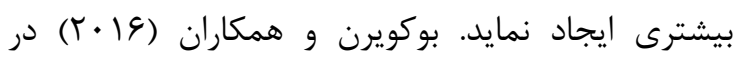

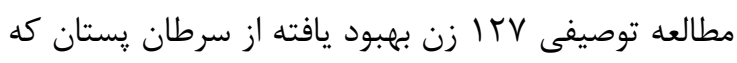

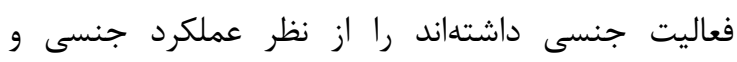

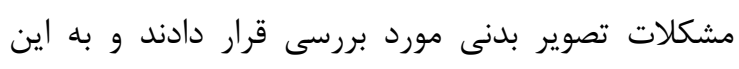

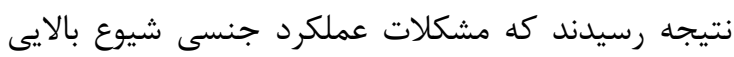


يزوهشكده معتمد جهاد دانشگاهى بود كه بين سالهاى rq تا هو زير ••ه سال داشته و بلهصورت طبيعى يائسه نشده بودند و بين دو ماه تا دو سال از زمان دان درمان آنان آنها

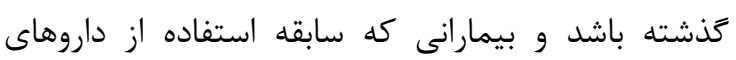

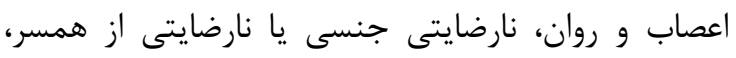

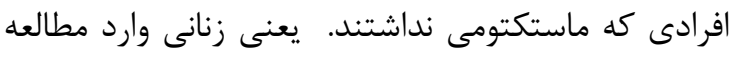

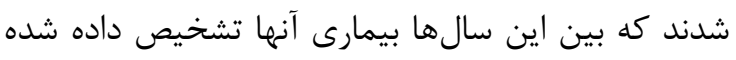

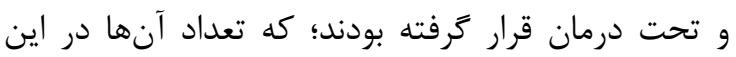

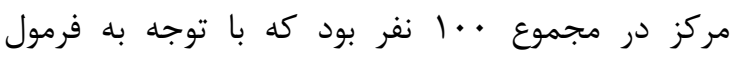

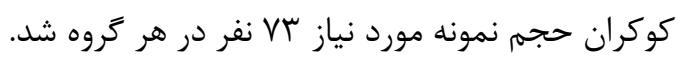

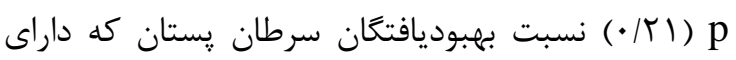

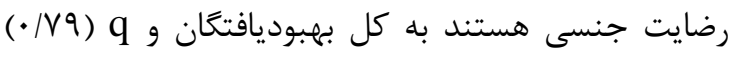

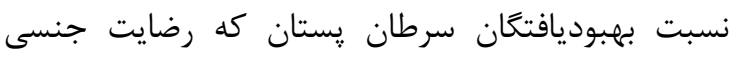

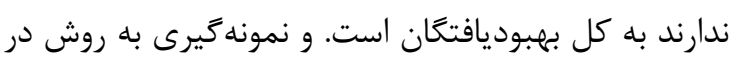

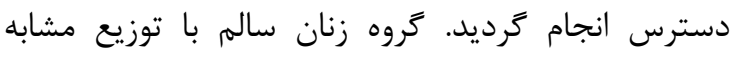

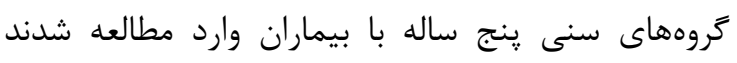

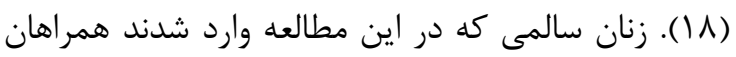

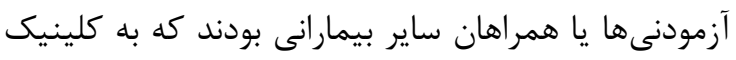

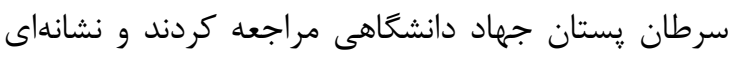
از بيمارى سرطان يستان در آنان وجود نداشت.

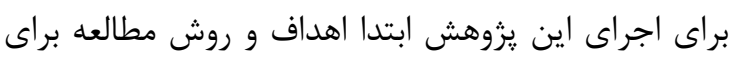

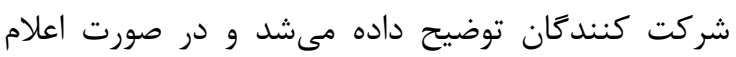

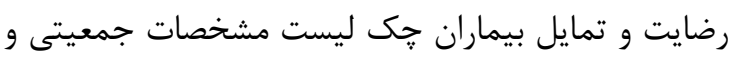

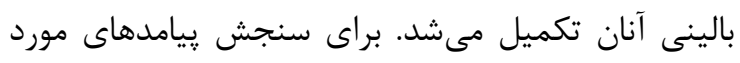

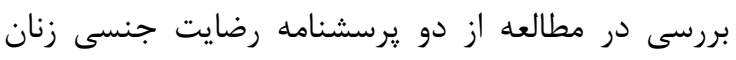
(SSSW')

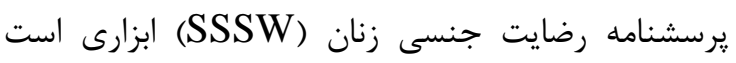

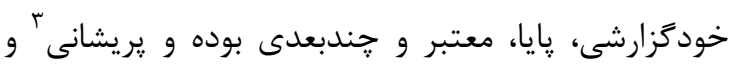

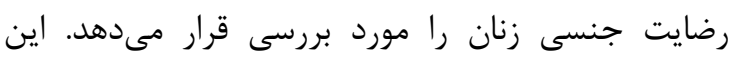

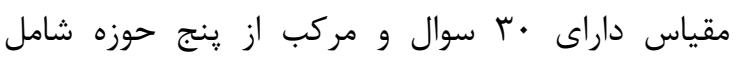

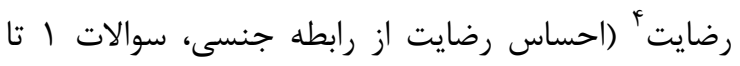

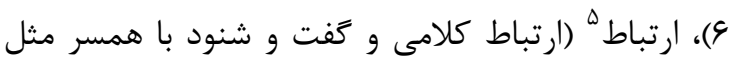
بيان راحت احساسات، انتقادات و ييشنهادات و ... در زمينه

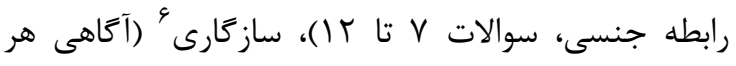

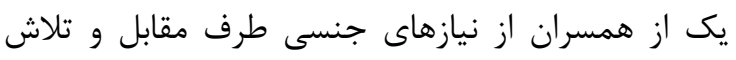

\footnotetext{
${ }^{1}$ sexual satisfaction scale for women

${ }^{2}$ body image concern inventory

${ }^{3}$ sexual distress

${ }^{4}$ contentment

${ }^{5}$ communication

${ }^{6}$ compatibility
}

بدنى شود. يرتونعارى ممكن است باعث آسيب به بافت و

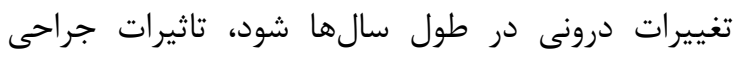
بيشتر فورى اما اغلب ماندكار هستند، در حالى دالى كه

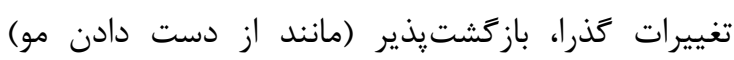
ممكن است ناشى از شيمىدرمانى نظامدار باشند. تغييرات

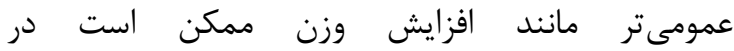

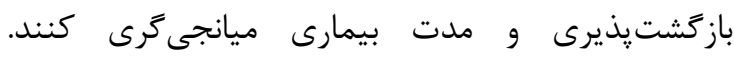

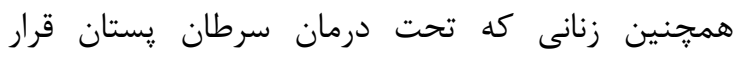

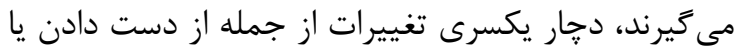

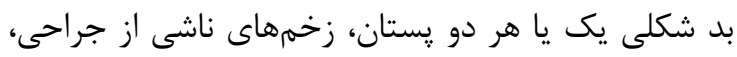

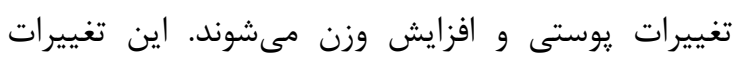
ارتباط بسيار نزديكى با ظاهر فيزيكى و تصوير بدنى دارند

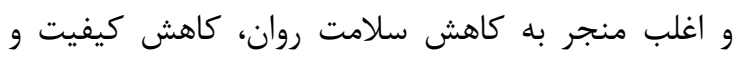

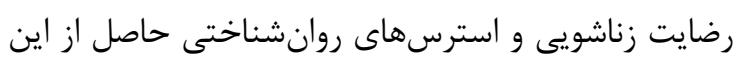

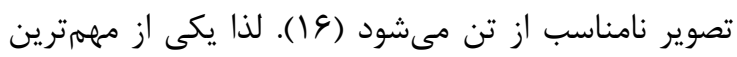

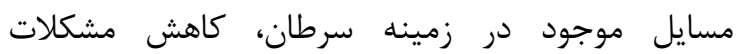

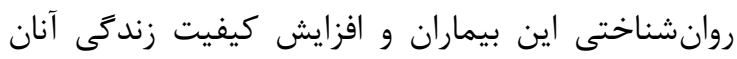

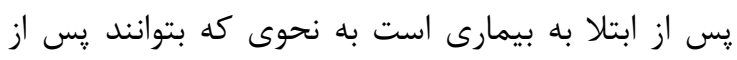

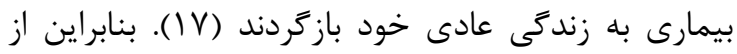

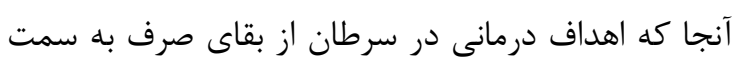

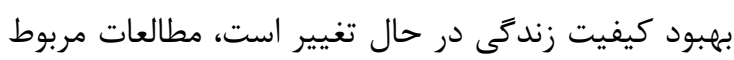

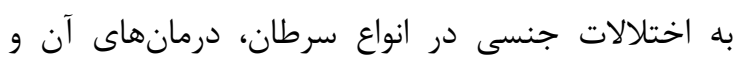

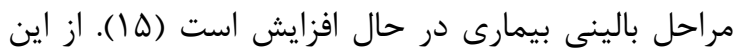

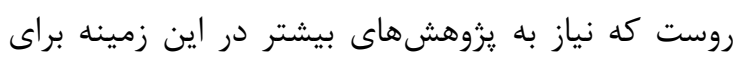

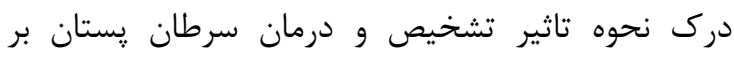

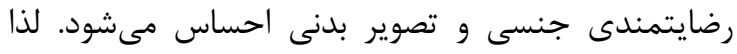

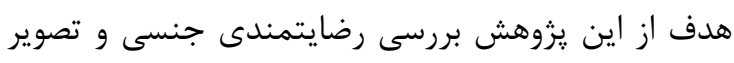

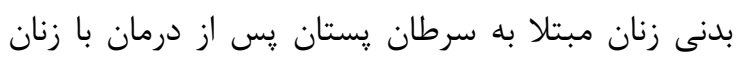

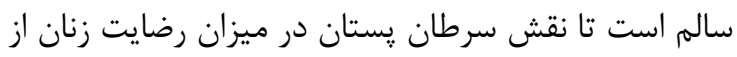

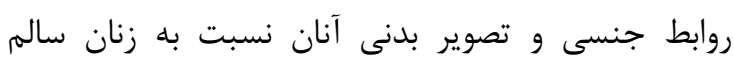
بيشتر مورد بررسى قرار كيرد.

\section{مواد و روشها}

يزوهش حاضر از نوع مقطعى و مقايسه دو گروه بود كه با هدف تعيين و مقايسه رضايتمندى جنسى و تصوير بدنى در زنان مبتلا به سرطان يستان پِ إن از درمان با زنان سالم

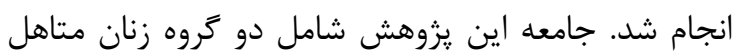

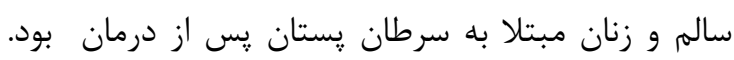

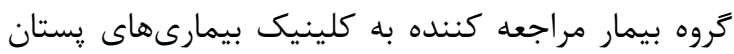


با استفاده از آزمون كولموكروف اسميرنوف مشاهده شد كه متغير هاى رضايتمندى جنسى و تصوير بدنى توزيع نرمالى داشتند لذا براى مقايسه ميانكَين توزيع آنها بين دو كروه از آزمون تى استودنت استفاده شد.

\section{يافتهها}

مشخصات شركتكنندكان در اين مطالعه در گروه زنان

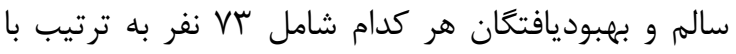
ميانكَين سنى

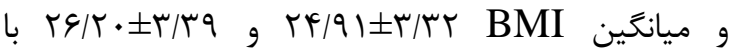
(p<0.022) نتايج مشخصات دموكرافيك اين يزوهش در جدول شماره ا آمده است. متغيرها شامل شغل، شهر، تعداد فرزندان، ميزان تحصيلات، نوع درمان (شيمىدرمانى، راديوترايى، هورمون درمانى) و قاعدىى بودند. متغيرهاى كيفى در متغيرهاى دموكرافيك با استفاده از

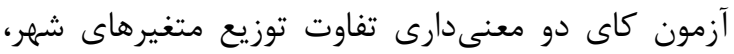

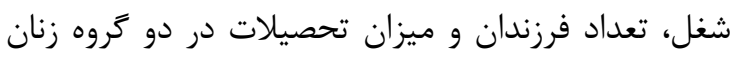

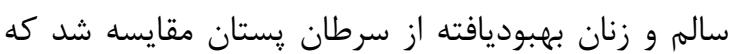

$$
\text { نتايج آن در جدول شماره آنان بـد آمده است. }
$$

اغلب شركت كنندكان در اين مطالعه ساكن شهر تهران و

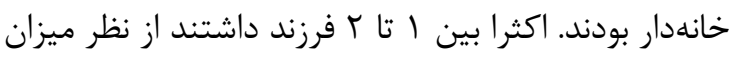
تحصيلات تفاوتى بين دو كروه سالم و بيمار وجود نداشت. نوع درمانى كه دريافت كرده بودند غالبا شيمىدرمانى و ودرد

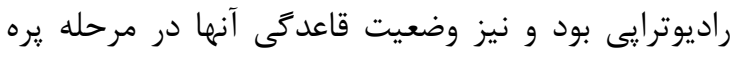

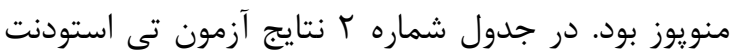
براى مقايسه ميانكين متغيرهاى رضايتمندى جنسى و آنداره

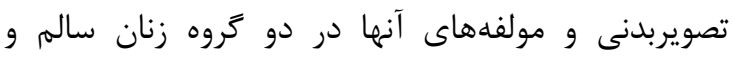

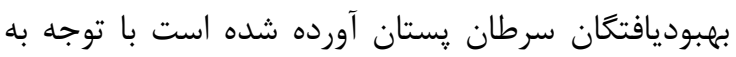

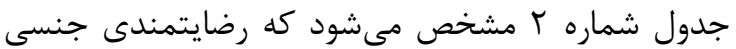

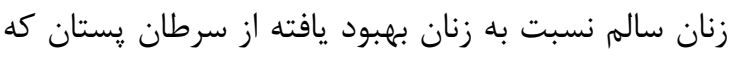

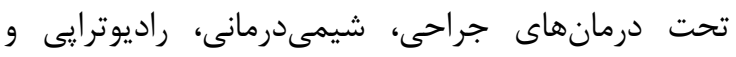

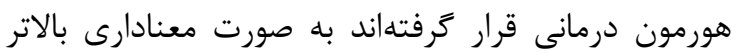
است. در اين קرسشنامه نمره بالاتر كه در تروه سالم

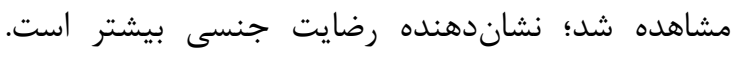
همجنين تصوير بدنى زنان سالم نسبت به زنان بهببود يافته

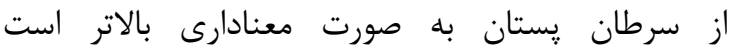
. $(\mathrm{p}=0.001)$
براى سازگار شدن با او در رابطه جنسى، سوالات سا تا

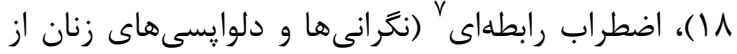
همسرشان به جهت وجود مشكلات و مسايل جنسى در زن و روى آوردن همسر به روابط خارج از خانواده، سوالات

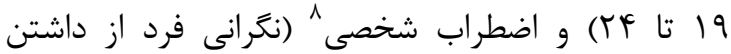
مشكلات جنسى خويش و ميزان تاثير آن بر ساير ابعاد

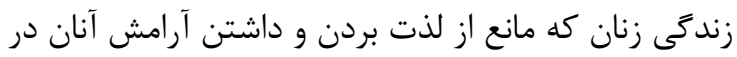

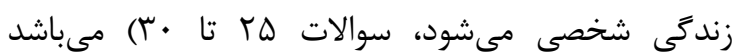

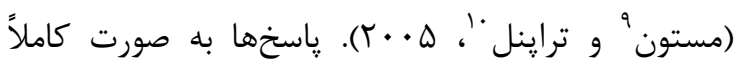
موافق (1)، كمى موافق (Y)، نه موافق و نه مخالف (Y)،

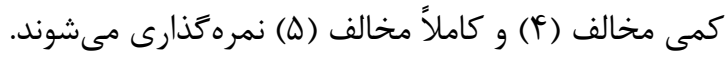

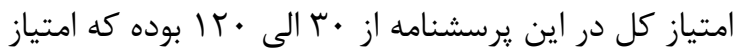
״ايينتر نشاندهنده عدم رضايتمندى جنسى و نمره بالاتر

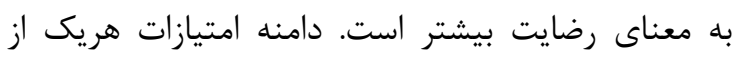
زيرمقياسهاى اين يرسشنامه 9 الى • ب مىباشد.

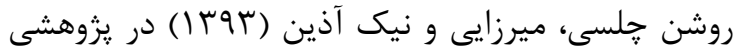

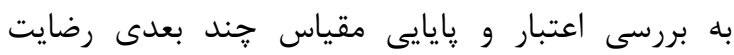

جنسى زنان (SSSW) در زنان ايرانى يرداختهاند (19 (1). ابزار ديكرى كه در اين يزوهشى مورد استفاده قرار گرفت

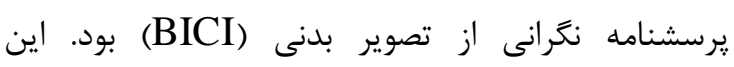

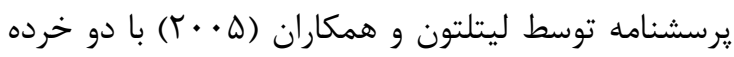

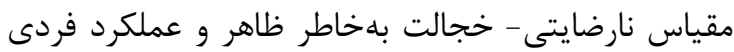
ضعيف به دليل نكرانى از ظاهر طراحى شده است. در ايران

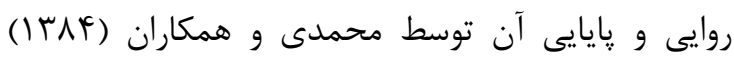

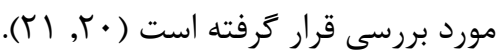

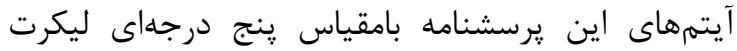

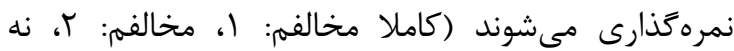

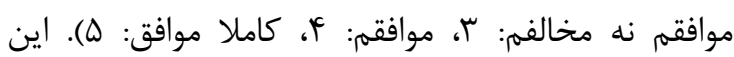
يرسشنامه داراى دو خرده سنجش نارضايتى ظاهر (11)

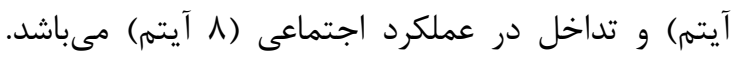

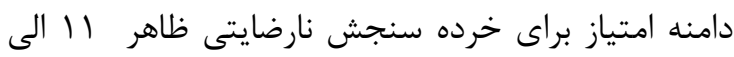

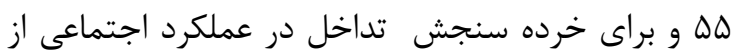

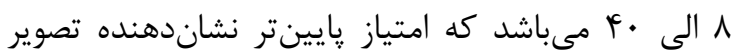

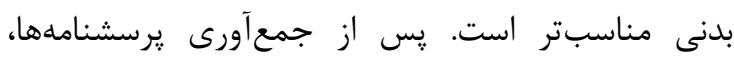

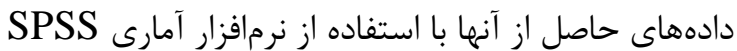
در سطح اطمينان هـ٪ مورد تجزيه و تحليل قرار كرفت.

\footnotetext{
${ }^{7}$ concern- relational

${ }^{8}$ concern- personal

${ }^{9}$ Meston

${ }^{10}$ Trapnell
} 
جدول ا: مقايسه متغير هاى كيفى در دو كروه زنان بهبود يافته از سرطان و زنان سالم

\begin{tabular}{|c|c|c|c|c|}
\hline \multirow{2}{*}{ P-value } & بيمار & سالم & \multirow{2}{*}{\multicolumn{2}{|c|}{ متغير }} \\
\hline & تعداد (درصد) & تعداد (درصد) & & \\
\hline \multirow{2}{*}{. IGAr } & $\Delta 9(/ . \wedge 1)$ & $\Delta \vee(/ . \vee \wedge)$ & ت تهران & \multirow{2}{*}{ شهر } \\
\hline & $14(/ .19)$ & $19(/ . T Y)$ & شهرستان & \\
\hline \multirow{2}{*}{$\cdot 1 \cdot \cdot \Delta$} & $r \Delta(/ . M Y)$ & $\operatorname{cr}(/ . \Delta V)$ & 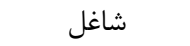 & \multirow{2}{*}{ 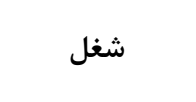 } \\
\hline & $\forall \wedge(1.99)$ & rI(\%) & خانهدار & \\
\hline \multirow{3}{*}{$\cdot \mid r q 1$} & $r(/ . \varphi)$ & $4(/ . \Lambda)$ & • & \multirow{3}{*}{ تعداد فرزندان } \\
\hline & $\Delta F\left(/ V F^{\mathcal{F}}\right)$ & $\Delta \vee(/ . \vee \wedge)$ & $1-r$ & \\
\hline & $19(/ . T T)$ & $1 \cdot(/ .1 f)$ & $r-f$ & \\
\hline \multirow{2}{*}{$\cdot / 1 \wedge \Delta$} & $\operatorname{Fr}(/ . \Delta \Lambda)$ & $M F(/ . F V)$ & زيردييلم و دييلم & \multirow{2}{*}{ ميزان تحصيلات } \\
\hline & YI (JFT) & 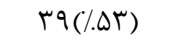 & بالاى دييلم & \\
\hline \multirow{3}{*}{-} & $90(/ . \wedge 9)$ & - & شيمىدرمانى & \multirow{3}{*}{ نوع درمان } \\
\hline & $\varphi \varphi(1.9 \mu)$ & - & راديوترايى & \\
\hline & $r \varphi(/ . r \varphi)$ & - & هورمون درمانى & \\
\hline \multirow{2}{*}{-} & $\operatorname{sf}(/ . \Lambda \Lambda)$ & $V r(/.) \cdots)$ & يره منويوز & \multirow{2}{*}{ وضعيت قاعدگى } \\
\hline & $9(/ .14)$ & - & "*"منويوز & \\
\hline
\end{tabular}

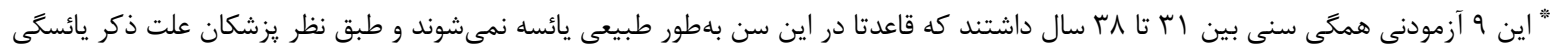

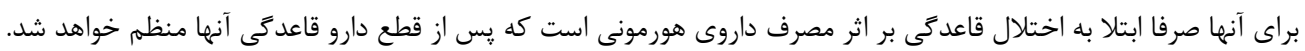

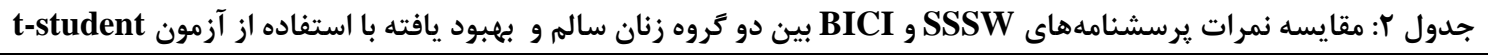

\begin{tabular}{|c|c|c|c|c|c|}
\hline \multirow{3}{*}{ P-value } & \multirow{3}{*}{$\mathbf{t}$} & 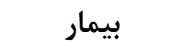 & سالم & \multirow{3}{*}{ متغير } & \\
\hline & & ميانغين & 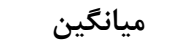 & & \\
\hline & & (انحراف معيار) & (انحراف معيار) & & \\
\hline$<\cdot 1 \cdot \cdot 1$ & $V / 9 V$ & $\mid N / \Lambda F \pm \varepsilon / \Lambda F$ & $r \varepsilon / \Gamma G \pm F / r G$ & رضايت & \multirow{5}{*}{ رضايتمندى } \\
\hline$<\cdot 1 \cdot \cdot 1$ & ( & $r \mid / \cdot 1 \pm \Delta / r \Delta$ & $r F / V \Delta \pm \Delta / \cdot \Lambda$ & ارتباط & \\
\hline$<\cdot / \bullet \cdot 1$ & F/ve & 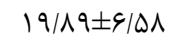 & $T \Delta / \cdot I \pm E / F T$ & ساز كارى & \\
\hline$<\cdot 1 \cdot \cdot 1$ & $\Delta / \mathcal{A}^{\mu}$ & $r / / 9 T \pm \varepsilon / \Gamma r$ & $r \varepsilon / \Lambda V \pm F / \Delta T$ & 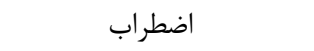 & \\
\hline$<\cdot 1 \cdot \cdot 1$ & $V / \cdot r$ & $\Lambda \cdot 19 \cdot \pm r \cdot 19 r$ & $1 \cdot r / A Y \pm \mid V / \cdot G$ & نمره كل رضايتمندى جنسى & \\
\hline$<\cdot 1 \cdot \cdot 1$ & $-r / v q$ & $r \Delta / r \Lambda \pm 1 \cdot / 4 \varphi$ & $19 / 94 \pm \varepsilon / 4 \Delta$ & \multirow{3}{*}{ تداخل در عملكرد اجتماعى ناريتى ناهر كل تصوير بدنى } & \multirow{3}{*}{ تصولفه تصاى } \\
\hline $.1 \cdot 1 \mathrm{f}$ & $-T / \omega$. & $r \cdot 109 \pm V / r r$ & $I V / Q \cdot \pm \Delta / \Delta T$ & & \\
\hline$\cdot 1 \cdot \cdot 1$ & $-r / \Delta \cdot$ & $49 / 11 \pm 19 / 99$ & $r \vee / \wedge \Delta \pm 1 \cdot / \wedge \Delta$ & & \\
\hline
\end{tabular}

نشاندهنده رضايت جنسى بيشتر است. و هر أ مولفه آن يعنى رضايت، ارتباط، سازگًارى و اضطراب نيز نمره بالاترى دارند. تصوير بدنى بر اساس يرسشنامه BICI داراى ب ب مولفه

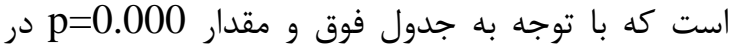
مولفه نارضايتى ظاهر و مقدار p=0.014 در مولفه تداخل در عملكرد اجتماعى مشخص مىشود كه تصوير بدنى زنان

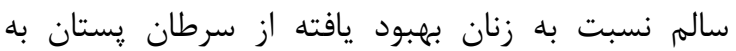
صورت معنادارى بالاتر است.
و در مورد مولفههاى رضايتمندى جنسى نيز بايد كفت كه بر اساس :رسشنامه SSSW رضايتمندى جنسى داراى مولفه است كه با توجه به جدول شماره r و مقدار

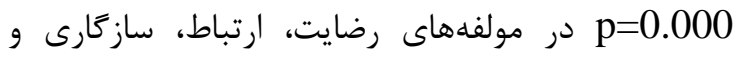

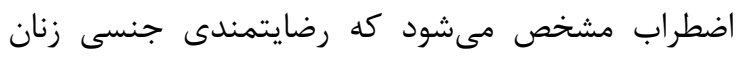

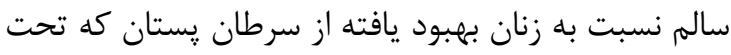

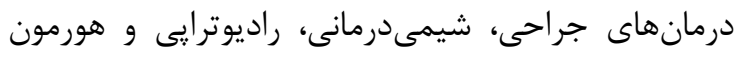

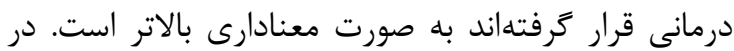

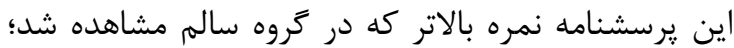


مطالعات قبلى نشان دادهاند بين رضايتمندى جنسى زنان مبتلا به سرطان يستان و زنان سالم تفاوت معنىدارى وجود داردكه مطالعه حاضر نتايج اين مطالعات را تاييد

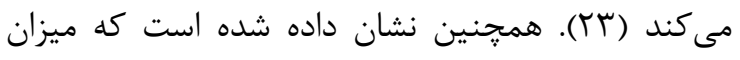
رضايت از رابطه زناشويى قبل و بعد از ابتلا به سرطان

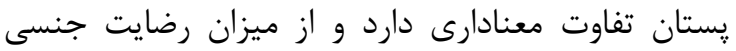

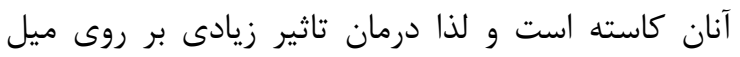

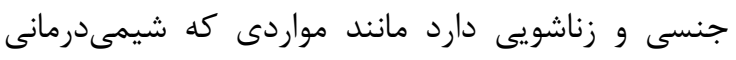

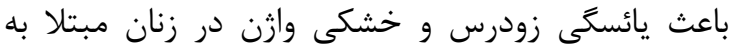
سرطان يستان مىشود (YF).

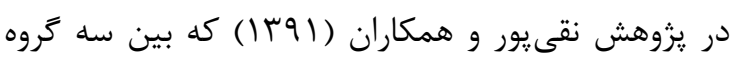
زنان سالم، ماستكتومى شده و جراحى حفظ يُتان انجام شد، در متغيرهاى رضايت جنسى و تصوير بدنى تفاوت معنادارى وجود نداشتنتايج اين تحقيق نشان داد داد كه

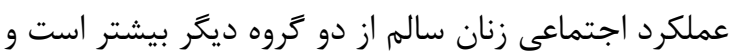

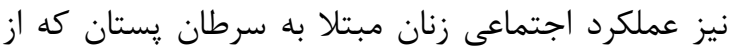

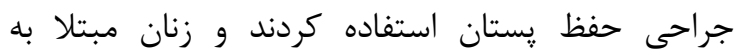
سرطان يستان كه از جراحى ماستكتومى استفاده كردهاند،

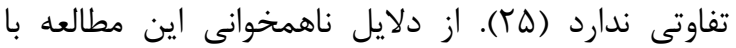

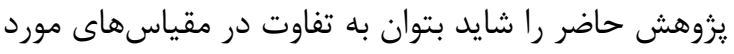

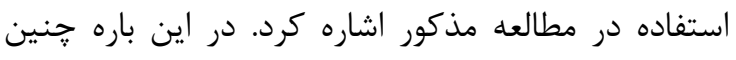
مىتوان استدلال كرد كه برخى خرده مقياسهای يرسشنامه انريج كه در مطالعه نقى يور و همكاران بهكار

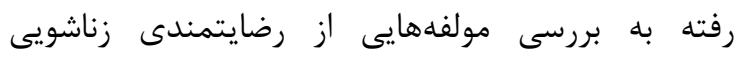
(جهت گيرى مذهبى، فرزنديرورى، اختلافات و تعارضات

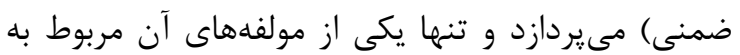

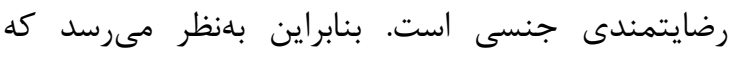

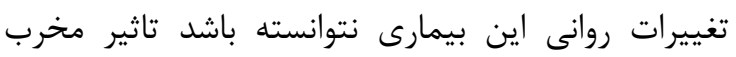
زيادى بر اين عناصر كذاشته و لذا تفاوت معنى دارى بتى بين دو كروه سالم و بيمار بيدا نكرده باشد. در حالى كه مقياس

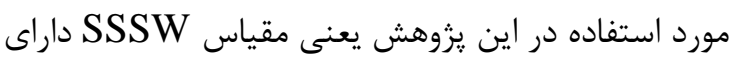
مولفههاى رضايت، ارتباط، سازكارى، اضطراب شخصى مفي و اضطراب رابطهاى است كه بهنظر مىرسد كمتر تحت تاثير

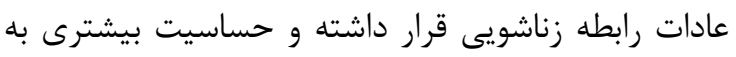

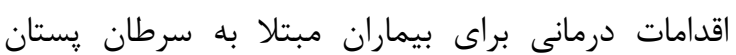
داشته باشد.

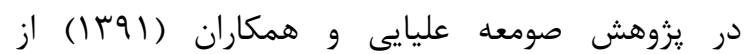

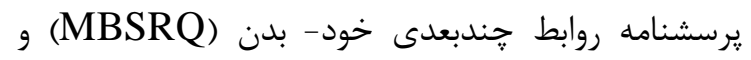

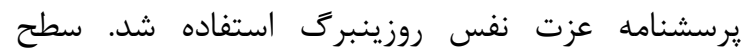

اين يزوهش از نوع مقطعى (توصيفى - تحليلى) بود و

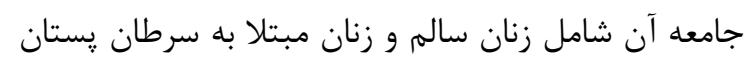

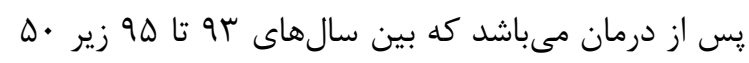
سال داشتهاند. نتايج حاصل از يزوهش حاضر بيانكر تفاوت

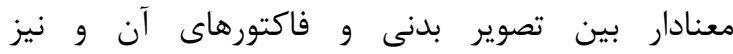
رضايتمندى جنسى و فاكتورهاى مربوط به آن بين زبن زنار لنان

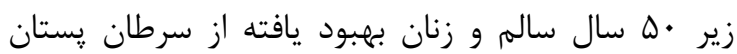

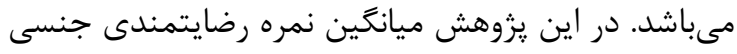

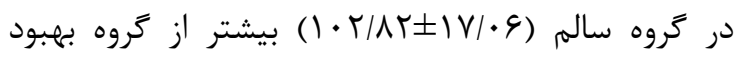

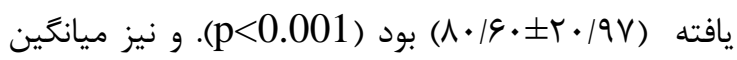
تصوير بدنى در كروه سالم

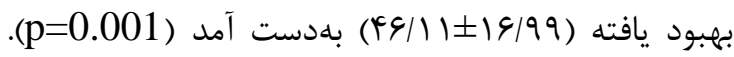
اين تفاوت معنى دار در كليه مولفههاى هر دو متغير نيز معنادار به دست آمد (

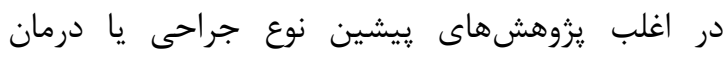

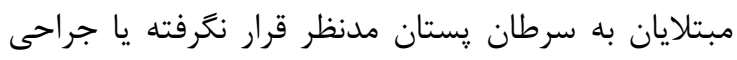

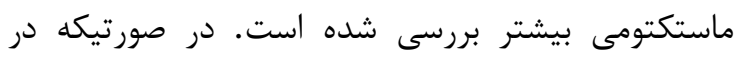

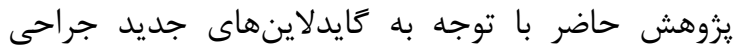

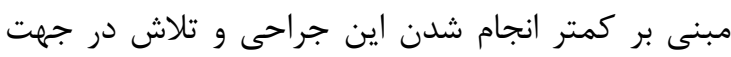

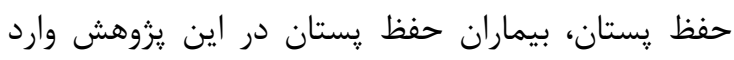

شند. در يزوهش شايان و همكاران (هوبا) مولفههاى عملكرد

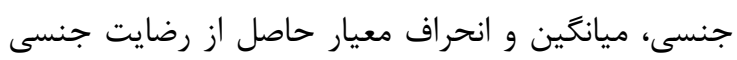

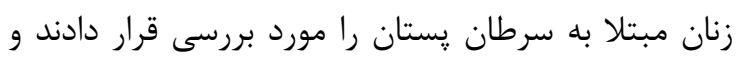
به اين نتيجه رسيدند كه سرطان يستان مىتواند عملكرد برد

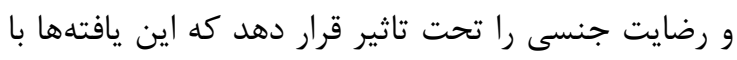

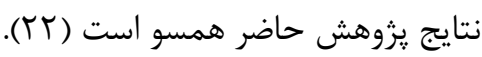
در اين يزوهش 9 نفر از شركت كنندكان در كروه بيماران

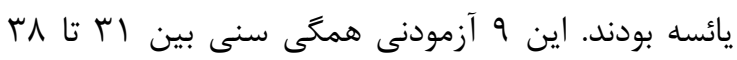

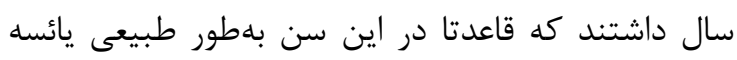
نمى شوند و طبق نظر يزشكان علت ذكر يائسكى براى آنها

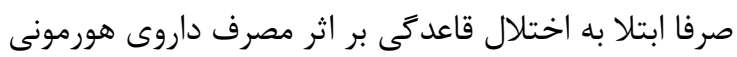

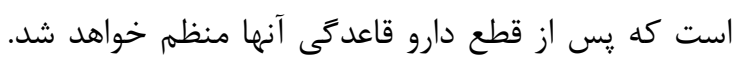

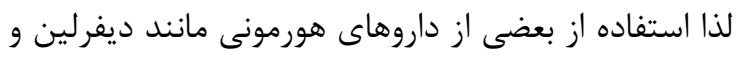

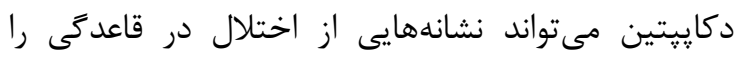

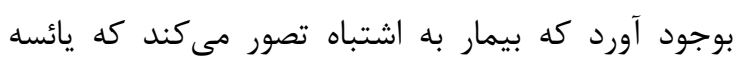

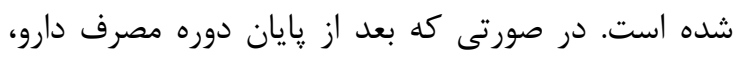

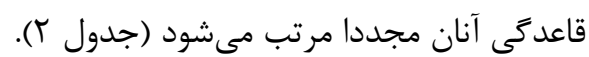


اقتصادى، باورهاى فرهنكى و مذهبى، يذيرش همسران كه در رضايتمندى جنسى نقش دارند، بررسى شود.

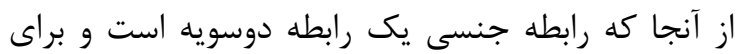
داشتن رضايتمندى جنسى بايد ديدگًاه همسران نيز مورد

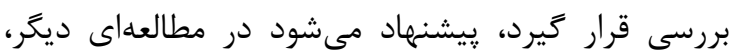
نقش حمايتخرى همسران زنان بهبود يافته از سرطان يستان و سنجش ميزان ميل و رضايت جنسى آنان در قبل ئل و يس إز ابتلاى زنان به سرطان يستان نيز در ايران

سنجيده شود.

با توجه به اينكه حين انجام مطالعه موارد و نشانههايى از

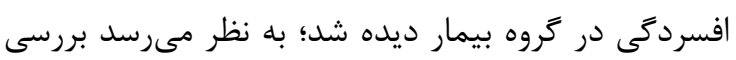

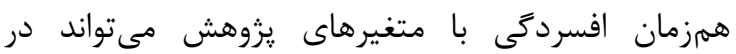

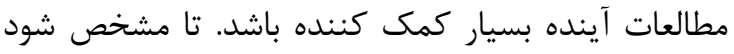

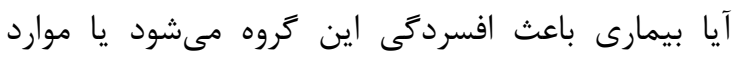
زمينهاى ديگرى نيز وجود دارد. با توجه به موارد كفته شده؛ شناخت و اقدامات درمانى در مورد اختلال تصوير بدنى و ايجاد شرايط مطلوب و و آموزش هاى لازم براى بهتر شدن ارتباط زناشويى زوجين و از بين بردن باورهاى غلط رايج بين بيماران در ارتباط با

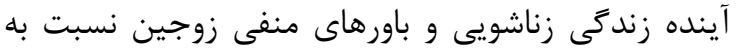

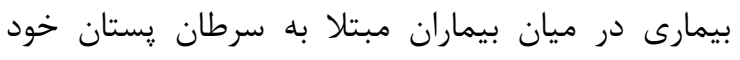
عاملى مىشود كه همراه با مشكل بيمارى، ساير مشكلات روانشناختى (كاهش كيفيت زندگى زناشويى، كاهش اعتماد به نفس، خودينداره منفى) بهوجود نيايد.

\section{نتيجهكيرى}

يافتههاى اين يزوهش نشان مىدهد بين تصوير بدنى و

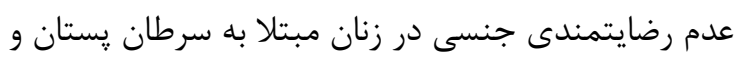

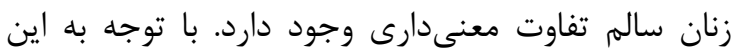
موضوع؛ بهتر است در كنار اقدامات درمانى براى اين بيماران، كادر حمايتى در جهت تعديل اثرات روانشناختى

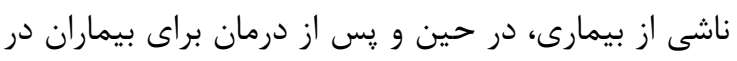

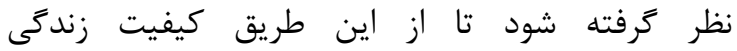
بهبوديافتگان سرطان يستان در وضعيت مطلوبترى قرار كيرد.
معنادارى بهدست آمده حاكى از آن است كه بين هيج يك ته از مولفههاى تصوير بدنى دو گروه زنان مبتلا به سرطان يستان با جراحى ماستكتومى و حفظ ״ستان، تفاوت معنادارى وجود ندارد. بنابراين مىتوان كفت تصوير بدنى بنى

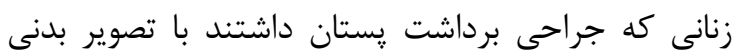
زنانى كه جراحى حفظ يستان داشتند متفاوت نيست (צ'). از دلايل ناهمسويى اين مطالعه با يروهش حاضر شايد بتوان به اين نكته اشاره كرد كه در اين مطالعه تصوير بدنى بين دو گروه از زنان كه هر دو نوع جراحى (برداشت و حفظ يستان) را داشتند صورت گرفته و و مقايسهاى با زنان سالم انجام نشده است. در صورتى كه در يزوهش حاضر شرط ورود به يزوهش، زنانى است كه فقط تحت جراحى حفظ يستان قرار گرفتهاند و اين دسته با زنان سالم مقايسه شدهاند بنابراين تفاوت معنادارى بين زنان بهبود يافته و زنان سالم از نظر متغير تصوير بدنى بوجود آمد. از محدوديتهاى مههم اين يزوهش اين بود كه به دليل تابو

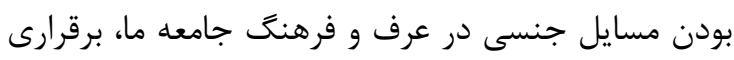
ارتباط با زنان بهبود يافته از سرطان يستان و حتى زنان

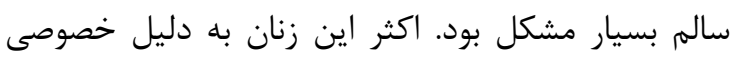
بودن سوالاتى كه در يرسشنامه SSSW كه مربوط به به به رضايتمندى جنسى است، تمايلى براى همكارى نشان نمى دادند لذا محقق براى اينكه بتواند اعتماد افراد را جلب ئب كرده و آنها را مطمئن سازد كه اطلاعات آنها محرمانه به بنه خواهد ماند، زمان زيادى براى جلب اعتماد آزمودنىها صرف كرد. همجنين در اين مطالعه دفعات و نوع باردارى

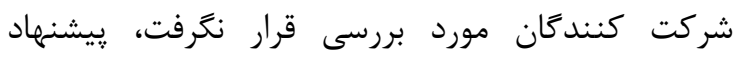

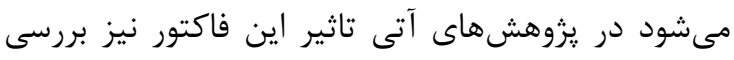
شود. از نقاط قوت اين مطالعه مىتوان به اين نكون نكته اشاره كرد كه بر خلاف مطالعههايى كه در اين زمينه وجود دارد،

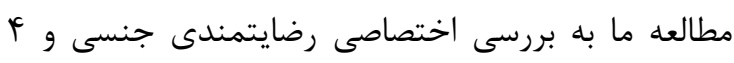

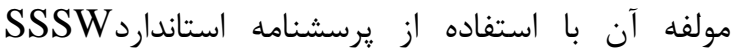
يرداخت. "يشنهاد مىشود در مطالعهاى ديخر، ارتباط ساير عواملى

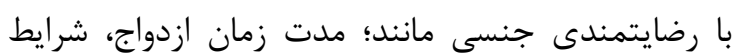




\section{References}

1. Grantzau T, Mellemkjær L, Overgaard J. Second primary cancers after adjuvant radiotherapy in early breast cancer patients: a national population based study under the Danish Breast Cancer Cooperative Group (DBCG). Radiotherapy and Oncology 2013;106(1)9-42.

2. Sharifibastan F. The Role of Cognitive Emotion Regulation and Positive and Negative Affect in Resiliency of Women with Breast Cancer. Iranian Journal of Psychiatric Nursing 2016; 4(2):38-49.

3. Mehrinejad S, Shariati S, Shapouri M. Stress in women with breast cancer compared to the healthy ones. CAPA 2010.

4. Khajehaminian F, Ebrahimi M, Kamali M, Dolatshahi B, Younesi SJ. Sexual functioning after mastectomy surgery-A qualitative study. Iranian Journal of Breast Diseases 2014; 7(3):17-25.

5. McLaughlin KA, Peverill M, Gold AL, Alves S, Sheridan MA. Child maltreatment and neural systems underlying emotion regulation. Journal of the American Academy of Child \& Adolescent Psychiatry 2015; 54(9):753-62.

6. Esfandiari Z, Joulaee A, Asli Azad M. A comparison of body image, marital satisfaction, and public health among breast cancer patients with breast evacuation, breast keeping and normal people in Tehran. Journal of health research in community 2015; 1(2):63-71.

7. Brunner and Suddarth's textbook of medicalsurgical nursing 10th edition 2004.

8. Burwell SR, Case LD, Kaelin C, Avis NE. Sexual problems in younger women after breast cancer surgery. J Clin Oncol 2006; 24(18):2815-21.

9. Boquiren VM, Esplen MJ, Wong J, Toner B, Warner E, Malik N. Sexual functioning in breast cancer survivors experiencing body image disturbance. PsychoOncology 2016; 25(1):66-76.

10. Harirchi I, Montazeri A, Bidokhti FZ, Mamishi N, Zendehdel K. Sexual function in breast cancer patients: a prospective study from Iran. Journal of Experimental
\& Clinical Cancer Research 2012; 31(1): 20.

11. Khosravi Olya T, Fallahchai R. Relationship between Dyadic Coping and Marital Quality in Women with Breast Cancer in Shiraz. Iranian Quarterly Journal of Breast Diseases 2018;10(4):59-68.

12. Male DA, Fergus KD, Cullen K. Sexual identity after breast cancer: sexuality, body image, and relationship repercussions. Current opinion in supportive and palliative care 2016;10(1):66-74.

13. Akbari M, Lotfi KF, Vaziri S. The efficacy of four-factor psychotherapy on increasing sexual self-esteem in breast cancer survivors 2017.

14. Bakht S. Comparison and comparison of body image and sexual dysfunction in women with breast cancer and healthy women: Al-Zahra University 2008.

15. Ebrahimi M. Evaluation of sexual function of breast cancer patients after treatment and its effective factors. Breast Cancer Reserch Center: ACECR 2012.

16. Rajabi G, Kaveh Farsani Z, Fadaei Dehcheshmeh H, Jelodari A. Psychometric Properties of the Persian version Scale of Body Image among Patients with Breast Cancer. Iranian Journal of Breast Disease 2015; 8(2):66-74.

17. Amini Kho M. An Investigation and Comparison of the Effectiveness of Narrative Therapy and Cognitive Behavioral Therapy on Physical Characteristics and Self-esteem of Women with Breast Cancer: Allameh Tabataba'i University 2008.

18. Molavi A, Hekmat K, Afshari P, Hoseini M. Evaluation of couples' sexual function and satisfaction after mastectomy. The Iranian Journal of Obstetrics, Gynecology and Infertility 2015; 17(134):17-24.

19. Roshan Chelsi R, Mirzaee S, Nik Azin A. Validity and Reliability of the Multidimensional Sexual Compliance Scale (SSSW) in a sample of Iranian women . Semi-annually Clinical Psychology \& Personality 2014; 21(10):11. 
20. Mohammadi N. The preliminary study of validity and reliability of Rosenberg's self-esteem scale. Journal of Iranian Psychologists 2005; 1(4):55-62.

21. Littleton HL, Axsom D, Pury CL. Development of the body image concern inventory. Behaviour Research and therapy 2005;43(2): 229-41.

22. Shayan A, Khalili A, Rahnavardi M, Masoumi Z. The relationship between sexual function and mental health of women with breast cancer. Scientific Journal of Hamadan Nursing \& Midwifery Faculty 2016; 24(4):221-8.

23. Bahmani B, Nghyee $M$, Ghanbari Motlagh A, Khorasani B, ehkhoda A, Ali Mohamadi F. Marital satisfaction in women with breast cancer during medical adjuvant therapy: A comparative study.
Scientific Journal Management System 2014; 3(9):1-12.

24. Nekoiefard O, Jahangiri L. Sexual function among patients with breast cancer Payesh 2014; 13(4):425-31.

25. Naghipour L, Zare M, Taghilou S, Heidari H. Comparison of Physical Imagination, Sexual Satisfaction and Quality of Life in Women with Breast Cancer, Psychological Social Studies in Women. Quarterly journal of Women's Studies sociological and psycological 2012; 10(4):41-62.

26. Some'eh Oliyaie R, KHodabakhshi Koolaie A, Akbari M, Kohsarian M, Kalhornia Golkar M. Body image and selfesteem: Comparing two groups of women with breast cancer. Iranian Journal of Breast Diseases. 2012;5(2):16-29. 